\title{
Canal through time: towards a multidisciplinary and holistic study of water systems?
}

\author{
L. Purdue ${ }^{1}$ F. Salomon ${ }^{2} \cdot$ J.-F. Berger ${ }^{3}$. \\ J.-P. Goiran ${ }^{4}$
}

Published online: 17 April 2015

(C) Springer Science+Business Media Dordrecht 2015

This special issue of Water History is the second of a set of two volumes dedicated to the theme: "Canal through time: a technological answer to socio-environmental variability?". These two publications derive from a workshop entitled «Diverting waters» which was organised on the 23rd and 24th of May 2012 at the Maison de l'Orient et de la Méditerrannée in Lyon, France. This workshop was sponsored by the CNRS, the University Lyon 2 and its Social Science Doctoral School, as well as the ANR research funding organisation.

The workshop addressed the question of the organisation and regulation of water systems in space and time. In order to provide for their food, energetic/industrial and commercial needs, societies have devoted major financial and human means to water diversion and channelling. Among the hydraulic structures built by communities, canals, at the interface between nature and culture, are a rich but still weakly-explored research object.

L. Purdue

louise.purdue@cepam.cnrs.fr

F. Salomon

ferreol.salomon@gmail.com

J.-F. Berger

jean-francois.berger@univ-lyon2.fr

J.-P. Goiran

jean-philippe.goiran@mom.fr

1 CNRS, UMR 7264 - CEPAM, Université de Nice Sophia Antipolis, Nice, France

2 Department of Archaeology, University of Southampton, Avenue Campus, Southampton SO17 1BF, UK

3 CNRS UMR 5600 - EVS-IRG, Université Lumière Lyon 2, 5, Avenue Pierre Mendès France, 69676 Bron Cedex, France

4 CNRS UMR 5133 - Achéorient, Maison de l'Orient et de la Méditerranée, 7, Rue Raulin, 69007 Lyon, France 
Canals appear as a structural element of the socio-political organisation of communities and their territory on various temporal and spatial scales (local to regional). There are also an image of a socio-economic system, technological skills, knowledge and representations. In parallel, the temporality of canals, such as their construction, maintenance and abandonment can be an adaptation and adjustment to short-term and/or long-term changing environmental conditions (climatic, hydrologic, and geomorphic).

The papers submitted to the journal Water History aimed to combine existing approaches to better integrate these anthropic structures to the study of socio-environmental interactions. The first volume of the workshop was published in March 2014 and was entitled "Roman Canal Studies'. The five papers published in this special issue revolved around this specific archetypical hydraulic society, and more precisely on methodological questions such as the identification of canals in the landscape (Bernigaud et al. 2014), their function (Bernigaud et al. 2014; Salomon et al. 2014; de Kort and Raczynski-Henk 2014), their spatial organisation and hierarchy (Bernigaud et al. 2014; Keay et al. 2014), as well as knowledge and know-hows involved in their construction (Bernigaud et al. 2014; Ruiz del Arbol et al. 2014; Salomon et al. 2014; de Kort and Raczynski-Henk 2014).

This second volume combines five papers which focus on areas where water represents a constraining resource, requiring the construction of hydraulic networks, mainly irrigation canals (B. Geyer and J.-Y. Montchambert in Irak/Syria, J. Charbonnier in Eastern Arabia, L. Purdue in Southwestern North America, N. Jacob-Rousseau in France, H. Farooqi and K. Wegerich in Pakistan), but also navigation canals (B. Geyer and J.-Y. Montchambert in Irak/Syria) and canals for energetic purposes (N. Jacob-Rousseau in France).

This second volume can be separated in two parts. The first part comprises three papers (B. Geyer and J.-Y. Montchambert, J. Charbonnier and L. Purdue) dealing with ancient water systems (last 4 millennia) in semi-arid to arid environments in the Near East, the Middle East and southwestern North America. In these constraining environments, hydraulic management is a necessity and shapes long-term land use as well as community organisation. Because of scarce textual archives, the authors use methods and tools such as archaeology and geoarchaeology to discuss the temporality (emergence, discontinuity) and technology of water management in regards to increasing population, the development of trade and exchange, as well landscape and climate change. The first paper written by B. Geyer and J.-Y. Montchambert focuses on the lower Euphrates valley and its early use during the 3rd millennium BC. Based mainly on a geomorphic and archaeological approach, the authors propose a regional synthesis linking environmental change, hydraulic development, mainly the construction of numerous types of canals, and the social, political and economic development of the kingdom of Mari. The paper written by J. Charbonnier, based on an archaeological approach, provides a large synthesis on the origin of a specific hydraulic technology (falaj) in southeastern Arabia (Oman and United Arab Emirates) taking into account environmental change and demographic contexts during the Bronze Age and Iron Age (last 2 millennia BC). The third paper written by L. Purdue focuses on the semi-arid American Southwest (Arizona), occupied by agricultural communities for the last two millennia. Using a chronological and geoarchaeological database, the author discusses the social and/or environmental factors that led to canal construction versus abandonment.

The second part of this volume is composed of two papers (H. Farooqi and K. Wegerich; N. Jacob-Rousseau). Based on a geohistorical approach (last 3 centuries), both manuscripts discuss the social (management, technology, day to day actions, conflict resolution) and environmental aspect (water scarcity, land use) of water systems in the context of social transformation (colonisation, agricultural/industrial intensification). These 
manuscripts provide an important framework to understand past water systems. By combining various written archives, N. Jacob-Rousseau aims to understand the impact of water management on the environment and on social issues in four regions of France (the Vivarais and the Roussillon on the Mediterranean frontage and the Morvan and the Alps in the Rhone Basin) from the end of the eighteenth century to the beginning of the twentieth century, in a context of agricultural and industrial intensification. Based on government reports and newspapers, the second paper, written by H. Farooqi and K. Wegerich, discusses the history of water rights, irrigation management at various scales, and land control in Punjab, Pakistan during British colonisation (nineteenth-early twentieth century).

The geographical scope and temporal diversity addressed by the authors allowed them to discuss three major questions: (1) Based on the available archives (textual, archaeological, sedimentological) and the data they can provide, which approach is appropriate to study past water systems from a socio-environmental perspective? (2) Which social body manages water systems? (3) How did human communities modify their management of water system as a result of fluctuating environmental conditions and/or social change?

\section{Which approach is appropriate to study past water systems from a socio-environmental perspective?}

The various approaches discussed in this volume propose different points of view on water systems and networks. While they rely mainly on history, geohistory, archaeology, geomorphology and geoarchaeology, the authors also occasionally use tools and data conducive to ethnology, hydrology, etc. Generally, the approaches and methods engaged depend on the initial research questions as well as the data available and their analysis. However, the lack of ready-to-use data, inherent to all studies of the past, does not allow researchers to directly answer their research questions. This lack also stimulates the development of new research tools and consequently, the rise of new questions.

Is there a way to combine these well-established as well as new methods to properly understand how the study of anthropic water systems can be inserted in socio-environmental studies?

When studying water systems and networks, the scale of study is extremely relevant. First, there are various spatial and temporal scales (hourly reconstructions versus long-term climatic change) involved in their dynamic. Second, numerous features of the systems (from their spatial organisation to their symbolic significance), which represent specific moments of their development, have to be reconstructed. Therefore, the data which need to be gathered is tremendous and numerous approaches should be combined.

In a materiality-based approach, archaeology is key to reconstruct water systems as technical systems and to understand their temporalities on the short- and long-term (construction versus abandonment). In parallel, the study of settlement pattern allow us to understand phases of land occupation and land abandonment, which can then be related to social and/or climatic factors. The archaeological method is however incomplete. While it is possible to consider the large picture, the society itself, it does not provide information on its structure nor its precise size, as short-term and long-term temporalities are often "crushed" in stratigraphy. The geoarchaeological and chronological study of water networks is another way of studying canals from this materiality-based perspective. At the interface between social and environmental dynamics, this approach combines both the 
social study of water systems (canal construction and design, phases of maintenance, canal abandonment) as well as the environmental conditions in which the canals were built, evolved and were abandoned (study of the sedimentary fill of the structure, from flood deposits to water stagnation and natural eutrophication). When building a water network, human communities took into account the constraints or advantages of the surrounding dynamic landscape (slope, fluvial terraces), subject to social and environmental changes (e.g. floods, downcutting events, fluvial metamorphosis, major water diversion that dries out the river). While reconstructing its evolution using a geomorphic approach allows us to understand the constraints communities had to cope with as well as large socio-environmental dynamics, it does not provide us with precise information concerning the water flowing into the structures, nor information on the socio-economic and political institutions that built the system.

The historical and geohistorical approaches provide information at various social scales. By studying written archives, it is possible to understand the social or economic factors that led to canal construction, management, maintenance and abandonment, from its legal aspect to the amount of water diverted. More precisely, the environmental history approach is key to estimate the social point of view of irrigation communities on their surrounding environment (impact of irrigation practice on the environment and impact of the environment on the practices). While this approach is extremely relevant and can provide keys of interpretation of past societies, it also requires a study of water networks in their materiality such as the archaeological and geoarchaeological approaches.

This opposition between materiality-based approaches (archaeology, geoarchaeology) and text-based approaches (history) is obviously a simplification. Historians, geohistorians, archaeologists and geoarchaeologists continuously create new modalities of thinking and applying interdisciplinarity. However, it is still a major challenge to think and overcome the gap between the reality of human perceptions and the materiality of socio-environmental interactions at different temporal and spatial scales.

\section{Which social body manages water systems?}

Water systems are man-made constructions, the work of a community, composed of individuals, groups of individuals, to construct, operate and maintain hydraulic structures. In order for these activities to be effective, specific social conditions need to be fulfilled as regards the conceptual design, construction and everyday functioning (operation and maintenance) of these systems. Design and construction depend on technological skills, often shaped by demands and needs, and social links. Operation and maintenance include water distribution rules (acquisition, allocation, distribution resources mobilization, and communication) and conflict management (Uphoff 1986). As soon as water is diverted or managed, social interactions are required, and the latter are structured around the formation of organizations (from community-based to government organizations), which allow us to link local activities to centralized decisions.

The presence of multiple levels of organization has been thoroughly established in water systems (Coward 1976, 1978; Geertz 1959; Si 1982) and, as a consequence, the scales of study can be multiple. At first however, it seems necessary to define and distinguish the social bodies that manage every day activities versus the ones that create water systems and provides administrative rules and norms (Uphoff 1986): A household, an institution, a 
state, a community? Four levels of organization which control water can be defined (Yeraswork 2000).

1. Water systems can be managed by individuals or small groups, who manage water at the level of conveyance and distribution, as well as in the field.

2. When water is considered as a common resource pool, farmers can act collectively. They can form organisations or associations, and manage the system from its operation and maintenance, to allocation strategies and conflict resolution. They traditionally distribute rights to the group and individuals, excluding non-members.

3. Within a communitarian management, rights are shared by members of a similar social group with a local authority (formal, informal institution or popular participation). Operation and maintenance requires coordination and collective action.

4. Last, water systems, from water distribution to everyday use can be managed by public authorities (state or local government).

The manuscripts presented in this volume put forward different types of management, when it is possible to reconstruct them. Both the textual and material approaches converge on the classification established by Yeraswork (2000), but the procedures to identify them are different.

In archaeological and geoarchaeological approaches, three main parameters for defining the social body are identified: (1) population; (2) hierarchy; (3) specialisation. Population is not the main topic of the articles in this Special Issue, but a semi-quantitative method is considered for estimating and expressing it. The length and width of canals as well as the size of networks are considered as a direct consequence of population size, due to the fact that they required -or not-large investments and cooperation. The number and size of the settlements linked to hydraulic structures and artefacts resulting from a large economical system are also considered when estimating past population sizes. Social complexity should not be considered as a consequence of population growth and associated "hierarchy" and "specialisation". In fact they exist at different scales in cultures and in different modalities.

In order to avoid these issues, authors use the term of "settlers" (B. Geyer et al.), in order to remain at the level of archaeological "settlements", and of "users" when referring to individuals using the canal systems (L. Purdue). The terms of "small groups" or "complex society" allows the authors to touch upon the real social complexity (B. Geyer et al., J. Charbonnier and L. Purdue). When written archives are available (B. Geyer et al.), specific persons can be referred to (governor, king) but the authors admit that establishing a link between the persons cited in the texts with the reality of the canal system management is difficult. An elegant opening is proposed by J. Charbonnier. He discusses a possible management of the falaj by describing current social structures.

In the case of historical sources, because of the large amount of data on social bodies, authors simplify it into general social groups or key social positions (N. Jacob-Rousseau, H. Farooqi and K. Wegerich). N. Jacob-Rousseau takes into account social complexity at the local scale in terms of stakeholders (institution, State, collectivities, central authority, small groups, household, riparians, administration arbitrator, engineers, population). The unregulated systems he mentions are controlled by agricultural communities or industrial groups. Water management is therefore private, with conflicts resolved by the State, which bases his decisions on nearly two century old laws, not adapted to evolving economic conditions. In the paper written by H. Farooqi and K. Wegerich, social complexity revolves around the stratification of the society (big landowners, irrigation bureaucracy, British administrator, chosen groups, senior officials, and selected elites). British administrators 
and influential local landlords control water allocation, canal maintenance and construction. However, the authors underline two external variables that have an impact on the social body that manages water systems at the local scale: land rights and technology.

\section{How did human communities modify their management of water system as a result of fluctuating environmental conditions and/or social change?}

The five manuscripts presented in this volume highlight that environment and the social body that manages water systems are in constant evolution. Water is an example of a common-pool resource which is finite, exhaustible. Cultural or environmental changes will lead to at least two issues on the long-term: resource provision and/or resource appropriation (Ostrom et al. 1994). For instance, increasing population will also increase transaction costs involved in monitoring and enforcing agreements among members (resource appropriation). Theory indicates that small to medium-sized groups may be able to better maintain the cooperation needed to manage an irrigation system than large groups (Ostrom et al. 1994). Also an increasing number of members in a group can lead to a larger amount of diverted water, and as a consequence, to resource provision issues.

B. Geyer and J.-Y. Monchambert in their manuscript consider their study area as a mosaic of geomorphic units with their own specificities, their own potentiality for exploitation ("exploitable", "arable", and "irrigable") and their own evolution through time. Human-environment relationships are here articulated around the terms "benefits and constraints". "Settlers" have the possibility of "location choices" (for the 3 period defined) with the ability of "planning" and creating "projects for territorial development" (especially for the 3rd period). "Communities" are characterized by population size (settlements type and density), but also on their "inventiveness" and "adaptability", related to "technological development" and territorial management.

The approach of L. Purdue takes into account the diversity of landscape potentialities but with a more systemic approach. Social systems, which constantly interact with their environment and modify it by consuming a resource or providing infrastructures, are considered as complex adaptative systems, also referred to as socio-ecological system (SES), or anthroposystèmes in France (Lévêque and Van der Leeuw 2003). The humanenvironment interactions focus on estimating to which extent these interactions were sustainable on the long-term. Her manuscript focusses on how water networks and their temporalities (construction, maintenance, abandonment) evolve during phases of cultural changes and/or environmental shifts. She highlights that agricultural communities can adapt to high frequency social or environmental events (e.g. seasonal floods, slow increasing population). Communities in this context can anticipate change and progressively become more specialized as regards their hydraulic technology and agricultural production. The efficiency of this specialization can be put into question when low-frequency events occur, against which communities are not prepared to deal with (e.g. fluvial incision, colonization, migration). Within this work, it is proposed that adaptation to high frequency events decreases the adaptation to low frequency events, and vice versa. In the American Southwest, a major low frequency environmental event probably led to the centralisation of power, which did not favour the sustainability of the system. It appears in this case that human adaptation might increase temporarily the society's robustness, but these changes might also increase its vulnerability to other socio-environmental disturbances (Janssen et al. 2007; Levin 1999). 
The paper written by J. Charbonnier discusses another topic. It relates to the emergence of a specific water technology: the "falaj" (channeling of groundwater) and points out how difficult it is to find evidence of its origins during the pre-islamic period. In his reflexion, the author takes into account social and environmental evolutions, but the latter are mainly considered as contexts. J. Charbonnier focusses above all on archaeological evidences and on the complexity of the success of this technology in specific environments and culture. He argues that constraining environmental conditions and/or increasing population could favor (1) the success of some technological innovation, (2) the creation and the mutation of social organisations to manage water systems.

These three papers deal with human-environment complexity avoiding a deterministic point of view on changes and socio-environmental interactions: mostly against geographical determinism first, with possibilities to adapt and select specific territories (B. Geyer and J.-Y. Monchambert) or by discussing complex interactions between the water system, the hydrosystem, the climate, and the population (L. Purdue). The third paper (J. Charbonnier) avoids both geographical and historical determinisms by taking into account the specificity of technology, its origin and development.

Applied on a shorter period of time and in conditions of major social changes, recent human-environmental interactions are mostly controlled by cultural changes (population, organisation, technology) in the paper of H. Farooqi et al. and N. Jacob-Rousseau. Both papers study in depth the modalities of social interactions. H. Farooqi and K. Wegerich discuss the conditions of water management prior and during British colonisation. Initially, irrigation water was obtained using wells, collectively-owned and the system proved efficient. Water management evolved during British colonisation (circa 1850), as the latter got involved in existing canal systems. Their controlling strategy was to intervene as administrators but maintain social order by leaving agricultural elites to keep their control over water systems and local irrigators to build and maintain canals. After 1880, the conquest of new land by the British allowed them to gain control over both land and water. Only specifically selected agricultural elites, loyal to the Empire, had access to large plots of land, leading to strong inequities within the society. As irrigation networks grew bigger, the issue of water scarcity also increased. British irrigation engineers worked on preserving the equity of water distribution by developing new water allocation technology. Agricultural elites and influential landowners however kept parts of their rights and only lost partial control over the amount of water they diverted. The socio-political system in Punjab prevailed on technological development.

The paper written by N. Jacob-Rousseau highlights the impact of increasing technology (agricultural and industrial) on the management of water systems and on water diversion during the last two centuries. In his case studies, systems were locally unregulated. A public authority resolved conflicts based on old laws but only when public interest was at stake. Buying land implied buying water rights. In this constraining context, private water management and individual logic prevailed. This led to inequity based on social status, money and land ownership, and created conflicts.

Rich historical data allow researchers to have access to direct information on both the resource and associated social structure (water quantity/distribution, rights and strategy in history versus sediment study and structures organization in archaeological and geoarchaeological approaches; population versus settlements and structures). It is then possible to confront data such as water availability to conflicts of interests (N. Jacob-Rousseau), or land ownership to water management (H. Farooqi and K. Wegerich), building this necessary layout at the meeting point between landscapes and social body. 


\section{Perspectives of research-a transdisciplinary and holistic approach of water systems}

Material facts and mental realities result from overlapping nature and culture. Hydraulic systems, structures and networks addressed in this special issue are the product of mental conceptions embodied in the material world, and suffer the vicissitudes of this material reality. To have access to past realities of this type, two ways prevail: identifying traces left in the landscapes or extracting clues from historical records. However, merging both information is often difficult to achieve.

Determining issues a society coped with is fundamentally a historical question: what is the observed phenomenon and its significance? What solutions were adopted and were they adapted? Were the perceptions toward the issues correct? Solutions provided by a society revolve around two spheres: the mental one (channel systems structured around laws, rights or any social practice, and also symbolic) and/or the material one (the channel networks itself). Material solutions are visible thanks to past signatures and remains in the landscape. Historical studies on the other side show the consequences of such issues based on feedbacks from this material work into the mental world through perceptions (e.g. the magnitude of a disaster can be transcribed and appraised in many ways in the mental sphere).

Interdisciplinary research combining archaeological and environmental data on water systems are not systematically conducted but research is evolving on well-established methodological and epistemological foundations. Written archives can be found in some past cultures and allow for a refinement of our reflection. But for most archives (texts, structures, landscape morphologies, sediment...) the link between the mental and material world has disappeared.

A mutual interest towards unresolved issues of both the textual and the field approaches would bring new potentialities to interdisciplinary and transdisciplinary studies. The link between both approaches should not be based only on abstract research question but more at the level of the data for which we see the limits as experienced in archaeology, geoarchaeology and palaeoenvironmental studies around a common "strata paradigm". This requires deconstructing how research issues are analyzed today and replacing them by a functional and holistic norm of thinking including top quality tools from history, ethnology, archaeology, geoarchaeology etc. Such a work would also involve the creation of comparison grids on the modalities of human-nature interactions and their uncertainty. For example, to facilitate interdisciplinary discussions and transdisciplinary questions and feed these comparison grids, archaeological and geoarchaeological approaches should be applied more systematically to recent periods to provide data and references. A balance between textual data and field data should favor discussions, and provide first "grids" on human-nature interactions, which could then be refined, completed, discuss and progressively improved. These enhancements and adding of potential new "grids" would also include studies using unbalanced sets of data (e.g. for earlier periods lacking textual data). The papers integrated in this special issue of Water History, are part of and contribute to this transdisciplinarity and holistic approach on water-systems.

\section{References}

Bernigaud N, Berger JF et al (2014) Ancient canals in the valley of Bourgoin-La Verpillière (France, Isère): morphological and geoarchaeological studies of irrigation systems from the Iron Age to the Early Middle Ages (8th century bc-6th century ad). Water Hist 6(1):73-93 
Coward EW (1976). Irrigation institutions and organizations: an international bibliography. C. I. A. Mimeograph 49, Ithaca

Coward EW (1978) Research methodology in the study of irrigation organization: a review of approaches and applications. Seminar Report 18. Agricultural Development Council Inc., New York

de Kort JW, Raczynski-Henk Y (2014) The Fossa Corbulonis between the Rhine and Meuse estuaries in the Western Netherlands. Water Hist 6(1):51-71

del Árbol Ruiz, Moro M, Sánchez-Palencia Ramos FJ et al (2014) Water networks of Roman gold mines of Northwestern Iberian Peninsula. Water Hist 6(1):95-113

Geertz C (1959) Form and variation in Balinese village structure. Am Anthropol 60:991-1012

Janssen MA, Schoon ML et al (2007) Scholarly networks on resilience, vulnerability and adaptation within the human dimensions of global environmental change. Global Environ Change 16(3):240-252

Keay S, Millett M et al (2014) The canal system and Tiber delta at Portus. Assessing the nature of man-made waterways and their relationship with the natural environment. Water Hist 6(1):11-30

Lévêque C, Van der Leeuw S (2003) Quelles natures voulons-nous ?. Pour une approche socio-écologique du champ de l'environnement, Elsevier, Paris

Levin SA (1999) Fragile dominion: complexity and the commons. Perseus book, Reading

Ostrom E, Gardner R, Walker J (1994) Rules, games, and common-pool resources. University of Michigan Press, Ann Arbor

Salomon F, Goiran JP et al (2014) A harbour-canal at Portus: a geoarchaeological approach to the Canale Romano: Tiber delta, Italy. Water Hist 6(1):31-49

Si RY (1982) Community ressource management. Lessons from the Zanjera. University of the Philippine Press, Quezon city

Uphoff N (1986) Improving international irrigation management with farmer participation: getting the process right. Westview Press, Boulder

Yeraswork A (2000) Twenty years to nowhere: property rights, land management and conservation in Ethiopia. Red Sea Press, Lawrenceville 